\title{
Prevalence of Epidural Hematoma Following Cervical Epidural Injections in Interventional Pain Management Settings: Literature ReView With Two CASe Reports
}

\author{
Laxmaiah Manchikanti, MD ${ }^{1,2}$, Yogesh Malla, MDㄹ, Ramsin M. Benyamin, MD², and Joshua A. Hirsch, MD
}

Epidural injections are performed frequently in managing chronic neck pain secondary to disc herniation, spinal stenosis, discogenic pain, and post cervical surgery syndrome. Major risks and devastating complications have been reported with cervical transforaminal epidural injections. Cervical interlaminar epidural injections have been considered as safe and effective in managing chronic spinal pain of multiple origins. Epidural hematoma is one of the rare complications. Efforts at prevention of cervical epidural hematoma have focused on avoidance of the procedures or cessation of therapy in patients with bleeding disorders, on antiplatelet therapy, fish oil, and multiple other drugs. The guidelines from multiple organizations have provided variable recommendations regarding the need to stop nonsteroidal anti-inflammatory drugs (NSAIDs) including low dose aspirin and antithrombotic agents. The risks of thrombotic events have been reported to be higher than of bleeding during surgery or interventional techniques with discontinuation of antiplatelet therapy.

We looked at a 16 year span of cervical interlaminar epidural injections (2000 through 2015), performed in a single facility during which time there were two epidural hematomas. The first patient was managed conservatively while the second patient required surgical intervention. Both patients recovered without residual complications. During the same period, 2 cases of cardiovascular events were reported in our practice associated with the cessation of antithrombotic therapy. They also recovered without residual complications. Nevertheless, rapid diagnosis is crucial as manifested by increased or unusual axial pain at the site of injection which is often different from patient's previous experience.

Two cases provided a prevalence rate of $0.0085 \%$ $(2 / 23,552)$ over 16 years at this facility. Based on occurrence of the year, the prevalence was one of 2,604 cases, or $0.03 \%$, in 2012 and one of 2,287 cases, or $0.04 \%$, in 2015 . This provides a prevalence rate of 0.085 per 10,000 procedures. Even though complications are extremely rare, it is essential to weigh the risk benefit ratio of these procedures and select the patients with extreme caution and perform the procedures with diligence.

Key words: Interventional techniques, bleeding disorders, aspirin, antithrombotic agents, cervical epidural injection, cervical epidural hematoma
From : ${ }^{1}$ Pain Management Center of Paducah, Paducah, KY; ${ }^{2}$ University of Louisville, Louisville, KY; ${ }^{3}$ Millennium Pain Center, Bloomington, IL, and University of Illinois, Urbana-Champaign, IL; ${ }^{4}$ Massachusetts General Hospital and Harvard Medical School, Boston, MA

Author for correspondence: Laxmaiah Manchikanti, MD

Address: Pain Management Center of Paducah, 2831 Lone Oak Rd., Paducah, KY 42003

E-mail:drlm@thepainmd.com
Cervical epidural injections with or without steroids are commonly performed procedures used in the management of chronic neck pain secondary to either disc herniation, spinal stenosis, discogenic pain without facet joint pain, or post cervical surgery syndrome (1-7). The analysis of utilization patterns in the United States in the Medicare population showed 390 cervical and thoracic epidural procedures per 100,000 population in 2014 , with an increase of $104 \%$ of cervical interlaminar epidural injections from 2000 
to 2014. The evidentiary basis for cervical epidural injections has been established with randomized controlled trials and systematic reviews along with multiple observational studies with lidocaine alone or lidocaine with steroids (2-7). Two prospective evaluations $(8,9)$ studied the bleeding risk of interventional techniques in chronic pain over a period of 20 months in approximately 3,200 patients with 12,000 encounters and almost 18,500 procedures, and showed no reports of epidural hematoma also in the 2,376 cervical interlaminar epidural injections included. In a manuscript assessing practice patterns of perioperative management of antiplatelet and anticoagulant therapy in interventional pain management (10), reports showed that serious complications of thrombotic events were 3 times more frequent than bleeding complications with 162 thrombotic events and 55 serious bleeding complications from epidural hematomas. Further, this assessment also showed similar bleeding complications with epidural hematomas, whether antiplatelet therapy was continued or discontinued, with 26 hematomas in patients where it was continued and 29 in those where it was discontinued. However, the exact proportion of patients where it was discontinued was unknown.

An acute epidural hematoma was reported recently in the cervical spine after interlaminar epidural steroid injection despite discontinuation of clopidogrel for 2 weeks prior (11). The same patient had three prior uneventful epidural injections. The same authors also have reported an epidural hematoma in a patient receiving fish oil supplementation (12). Further, 3 cases of cervical epidural hematoma also have been reported (13).

The potential contributing effect of ketorolac and fluoxetine to a spinal epidural hematoma following cervical interlaminar epidural steroid injection was also reported (14). There also have been multiple other case reports of epidural or subdural hematoma following cervical epidural injections and numerous reports of iatrogenic epidural hematomas (9-35).

We report 2 cases of epidural hematoma in a large tertiary referral center performing over 23,000 cervical epidural injections from 2000 through 2015.

\section{CASE DESCRIPTIONS}

The first patient was a 68-year old 5'3", 200 lbs.,
Caucasian female with a BMI of 35.4. She suffered from chronic neck pain associated with headaches and radiation into the shoulder blades and upper back with some radiation into the upper extremities above the elbows. Prior to the procedure, her magnetic resonance imaging (MRI) showed marked degenerative changes of C5-6 and C6-7 with intervertebral disc space narrowing and osteophytosis. There was also Grade II anterior spondylolisthesis of C3 on C4 with $5 \mathrm{~mm}$ anterior subluxation, which was slightly decreased on extension. There was also Grade I spondylolisthesis of 2 to $3 \mathrm{~mm}$ with flexion at C4-5. Initially the patient underwent diagnostic cervical facet joint nerve blocks with a false-positive response, wherein she responded to the first set of blocks appropriately and inappropriately with the second block. Consequently, she was treated with cervical epidural injections on a 3 to 6 month basis from her initial evaluation performed in early 2005. She received a total of 11 epidural steroid injections, from 2005 to 2012, averaging less than 2 per year, including the one on 4/4/2012 with formation of epidural hematoma. The cervical epidural performed in 2012 leading to epidural hematoma was uneventful with the loss of resistance technique and entering the epidural space at $\mathrm{C} 6$ and $\mathrm{C} 7$ with a midline approach in an ambulatory surgery center. Appropriate placement of the needle was confirmed with injection of 2 $\mathrm{mL}$ of Omnipaque 240, showing good epidural spread without vascular uptake or subarachnoid entry. Subsequently, the patient received $5 \mathrm{~mL}$ of $0.5 \%$ lidocaine mixed with $6 \mathrm{mg}$ of non-particulate Celestone. While in the recovery room, the patient complained of aggravating pain in the neck radiating to the mid scapular area without neurological deficit. She was given $50 \mathrm{mcg}$ of fentanyl with application of ice packs in the cervicothoracic region. The pain resolved and the patient was discharged home in satisfactory condition. However, over a period of the next 6 hours, she started developing increased levels of pain in the cervical spine and weakness on the right side of her body. She was sent to the emergency room and an MRI was performed. This MRI, with and without contrast, showed an epidural hematoma with spinal cord compression at the C5 and C6 levels. There was possible spinal cord edema. Due to the lack of a local neurosurgeon, the patient was transferred to a tertiary center at a university hospital within 120 miles. She 
continued to be stable with no neurological deficit except for subjective weakness on the right side with continued moderate pain in the cervical spine area. During her transportation to the university hospital, she started improving with resolution of the weakness and pain being reduced to mild discomfort. She was managed conservatively at the university hospital and observed for 48 hours and subsequently discharged with no residual complications. She continues to be a patient at our center to date.

The second case was in 2015, in a 65-year old 5'2", $149 \mathrm{lbs}$. Caucasian female with a BMI of 27.2. She has been a patient at the center since 2007 . Her complaints were related to bilateral paravertebral neck pain which started in 1973 following a motor vehicle accident with intermittent radiation to both sides of the head associated with headaches and some radiation into the upper back and mild radiation into the upper extremities just below the shoulders without numbness, tingling, pins or needles, or weakness. Pain was exacerbated with neck extension, right lateral flexion, and left lateral flexion. Her baseline MRI showed cervical spondylosis with disc space degeneration at the C6-7 interspace, and multilevel anterior and posterior marginal osteophyte formation extending from C5 through C7. Following the comprehensive assessment, pain of facet joint origin was suspected and she was treated with cervical facet joint nerve blocks, which did not indicate facet joint pain. Consequently, she was treated with cervical epidural injections with lidocaine only on multiple occasions from 2007 to 2016, including the occurrence of the cervical epidural hematoma. Multiple risks have been reported with precautionary measures of stopping antithrombotic therapy with cessation therapy related to thrombotic complications in general $(8,10,15,16,23,36)$. In October of 2015 , she was treated with a cervical epidural injection. After entering the epidural space between $\mathrm{C} 6$ and $\mathrm{C} 7$ with the loss of resistance technique in a sterile operating room, Omnipaque $2402 \mathrm{~mL}$ was injected, which showed a good filling pattern into the epidural space without intravascular or subarachnoid filling. Following this, 5 $\mathrm{mL}$ of Xylocaine $0.5 \%$ preservative free was injected into the epidural space. She was discharged home without any complications; however, 3 hours after the procedure, she called and complained of moderate to severe pain in the cervical and thoracic region without weakness. Subsequently, she was advised to apply ice and also return to the center. When she returned to the center, she complained of severe pain. However, she had no neurological dysfunction. There was no swelling. There was no evidence of external bleeding. There was no significant tenderness in the area of the injection. Pain increased with flexion and extension. Her gait was normal. Consequently, she was treated conservatively with an $8 \mathrm{mg}$ of Decadron injection, $50 \mathrm{mg}$ of Demerol intramuscular injections, and $25 \mathrm{mg}$ of Phenergan intramuscular injections. She returned home and was comfortably resting for 3 hours; however, after 3 hours, she stated that she was feeling some weakness in upper extremities, even though it was not major. She was asked to immediately head to the local hospital and underwent emergency MRI with and without contrast. The MRI, as shown in Fig. 1 showed epidural fluid collection with rim enhancement in the posterior aspect of the spinal canal extending from $\mathrm{C} 5$ through $\mathrm{C} 7$. This was to the right of the midline. There was also some fluid collection directly behind the C3 vertebral body without definite enhancement. Subsequently, 8 hours after the epidural injection, she underwent emergency decompression for cervical epidural hematoma with C6 and C7 laminectomies and evacuation of the hematoma. She was discharged from the hospital with no residual complications. She continues to be a patient at the center and is treated with interventional techniques for symptoms related to the lumbar spine using caudal epidural injections. Her cervical spine symptoms are managed medically. Incidentally, it is worth noting that the cervical laminectomies have reduced her pain significantly.

\section{DISCUSSION}

We are reporting 2 cases of epidural hematoma. One patient required surgical decompression after discontinuation of antiplatelet therapy and the second patient had no bleeding disorders or any therapy interfering with coagulation. Both patients recovered without residual complications. This has provided a prevalence of $0.085 \%$ with 2 cases of epidural hematoma in 23,523 cervical epidural injections performed from 2000 to 2015. Based on the occurrence of the year, prevalence was one of 2,604 cases, or $0.03 \%$, in 2012 and one of 2,287 cases, or $0.04 \%$, in 2015. Multiple case reports have been presented 


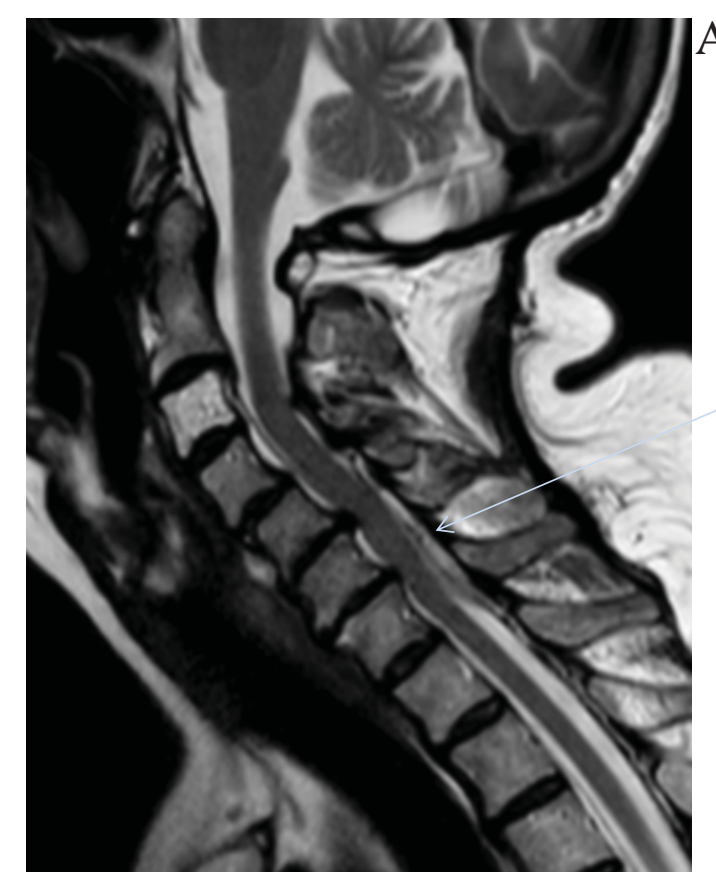

Sag T2WI demonstrating

epidural hematoma

extending from

approximately $\mathrm{C} 5$ to

approximately $\mathrm{T} 1$
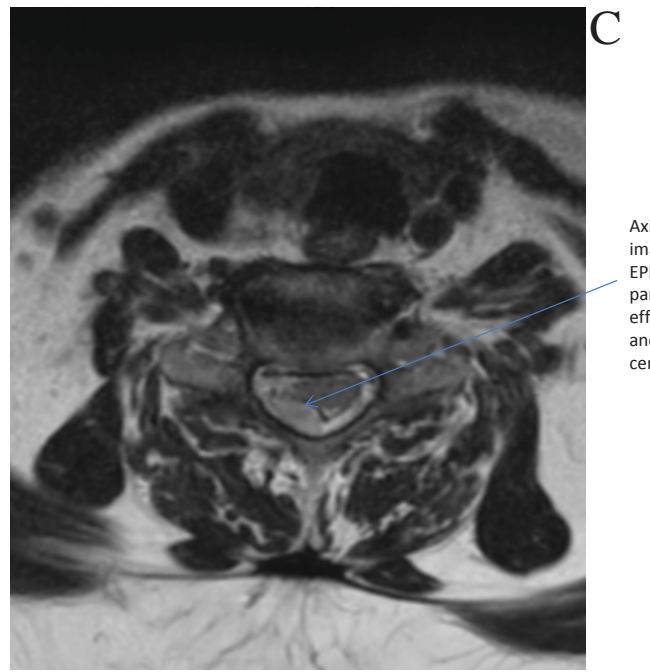

Sag post-contrast $\mathrm{T} 1$

weighted images

demonstrating

B

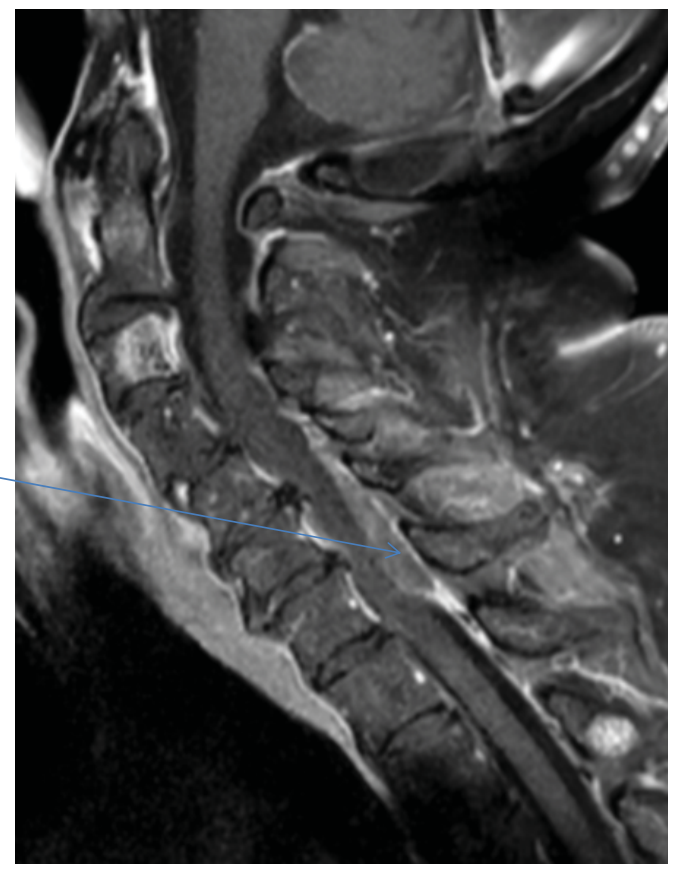

Axial T2 weighted

mage demonstrating

paracentral to the right

effacing the thecal sac

and distorting the

cervical cord

Fig. 1. MRI following cervical epidural injection with cervical epidural hematoma. 
in the past describing cervical epidural hematoma following interventional techniques (11-24). Among these, there was a single case of chronic subdural hematoma developing one month after the procedure (17). All but one of the cases (11-22) required surgical decompressions. In one case report, the potential contributing effect of ketorolac and fluoxetine was discussed (14). In another case (12), the influence of fish oil was reported. Overall, there are no published reports of cervical epidural hematoma developing in patients receiving antiplatelet therapy at the time of the cervical epidural injection, except for practice pattern surveys, which do not provide details. The literature has no prevalence statistics for cervical epidural hematoma, though a rate of 1.38 in 10,000 to 1 in 250,000 epidural procedures has been reported (14). Randomized controlled trials and large case series of cervical epidural steroid injections have not reported serious neurological complications including epidural hematoma. In a meta-analysis with inclusion of the relevant literature, the authors reported 4 cases of cervical neuraxial hematomas with 4 additional cases in the thoracic and lumbar spine (20). Our analysis in this report shows a single center prevalence of $0.085 \%$ for 10,000 procedures with 2 hematomas in 23,523 procedures performed from 2000 to 2015. The data derived from the closed claims project of the American Society of Anesthesiologists (ASA) showed 6 claims for paraplegia or quadriplegia due to epidural hematoma resulting from an interventional pain management procedure during the period between 1970 and 2000 (21). Other data also showed compressive epidural hematoma secondary to cervical epidural injections in 3 cases when the data was reviewed between 2005 and 2008 (22). None of these estimations will provide the appropriate prevalence of cervical hematoma related to epidural injections because multiple cases go unreported leaving the data underreported. Apart from antithrombotic therapy, multiple other mechanisms have been described leading to epidural hematoma formation. These are related to either epidural venous and arterial bleeding or bleeding from arterial venous malformations or anatomic abnormalities of the vertebral column with the posterior internal vertebral venous plexus being proposed as the most likely source of bleeding $(14,15,23,25,35)$. There have also been 3 case reports illustrating bleeding arising from arteries in the posterior longitudinal ligament following anterior discectomy (26). As described in interventional pain management practices and general medical literature $(8,10,13,15,35,36)$, the risk of thrombotic events may be higher with cessation of antithrombotic therapy. In our experience, we have faced 2 instances of cardiovascular thromboembolic complications with the patients recovering without residual complications after hospital admissions.

Other risk factors include anatomic abnormalities of the vertebral column, technically difficult or repeated epidural punctures, older age, intrinsic thrombocytopenia, or platelet dysfunction, renal failure, and coagulopathy related to hemophilia $(8,10,13,15,23,27-$ $31,35-37)$. Multiple safeguards to prevent neurologic complications, including a controversial consensus opinion from a multidisciplinary working group and national organizations, do not seem to prevent epidural hematoma formation (38-40). The literature also shows single epidural injections to be safer than continuous epidural injections. Thirty percent of the cases reported in the literature were related to idiopathic or spontaneous origin, $17 \%$ were related to anticoagulation, and only $10 \%$ were related to spinal or epidural anesthesia (31). Further, the majority of the cases were related to continuous epidurals in anticoagulated patients or in patients with thrombocytopenic disorders $(32,33)$. The literature shows that there have been at least 3 cases reported related to aspirin or other nonsteroidal anti-inflammatory drugs (NSAIDs), 2 cases related to low molecular weight heparin, and 2 cases related to fibrinolytic therapy. However, none of them were related to cervical epidural injections.

In reference to the anatomy, the cervical spinal cord is the most vulnerable to compression with defects in the dura because of the small diameter and small epidural space in this area compared to the thoracic and lumbar levels (34). Further, a wide anatomic variation also has been reported with arterial distribution in the cervical spine, which may increase such risk with interlaminar epidural injections, but most commonly with transforaminal epidural injections (37). Anatomical abnormalities such as cervical spondylosis and central and foraminal stenosis also may contribute to development of epidural hematoma after multiple attempts. Even though neither of these cases were 
associated with multiple attempts in performing the procedures, older age was a factor and both the cases showed significant spondylosis with osteophytosis.

\section{CONCLUSION}

Cervical interlaminar epidural injections are frequently used in managing chronic neck pain with or without upper extremity pain with local anesthetic alone or with steroids. Well known causes of epidural hematoma have been anticoagulation and antithrom-

\section{REFERENCES}

1. Manchikanti L, Pampati V, Hirsch JA. Utilization of interventional techniques in managing chronic pain in Medicare population from 2000 to 2014: An analysis of patterns of utilization. Pain Physician 2016; 19:E531-E546.

2. Manchikanti L, Nampiaparampil DE, Candido KD, Bakshi S, Grider JS, Falco FJE, Sehgal N, Hirsch JA. Do cervical epidural injections provide long-term relief in neck and upper extremity pain? A systematic review. Pain Physician 2015; 18:39-60.

3. Manchikanti L, Nampiaparampil DE, Manchikanti KN, Falco FJE, Singh V, Benyamin RM, Kaye AD, Sehgal N, Soin A, Simopoulos TT, Bakshi S, Gharibo CG, Gilligan CJ, Hirsch JA. Comparison of the efficacy of saline, local anesthetics, and steroids in epidural and facet joint injections for the management of spinal pain: A systematic review of randomized controlled trials. Surg Neurol Int 2015; 6:S194-S235.

4. Manchikanti L, Cash KA, Pampati V, Malla Y. Two-year followup results of fluoroscopic cervical epidural injections in chronic axial or discogenic neck pain: A randomized, double-blind, controlled trial. Int J Med Sci 2014; 11:309-320.

5. Manchikanti L, Cash KA, Pampati V, Wargo BW, Malla Y. A randomized, double-blind, active control trial of fluoroscopic cervical interlaminar epidural injections in chronic pain of cervical disc herniation: Results of a 2-year follow-up. Pain Physician 2013; 16:465-478.

6. Manchikanti L, Malla Y, Cash KA, McManus CD, Pampati V. Fluoroscopic epidural injections in cervical spinal stenosis: Preliminary results of a randomized, double-blind, active control trial. Pain Physician 2012; 15:E59-E70.

7. Manchikanti L, Malla Y, Cash KA, McManus CD, Pampati V. Fluoroscopic cervical interlaminar epidural injections in managing chronic pain of cervical post-surgery syndrome: Preliminary results of a randomized, double-blind active control trial. Pain Physician 2012; 15:13-26

8. Manchikanti L, Malla Y, Wargo BW, Cash KA, McManus CD, Damron KS, Jackson SD, Pampati V, Fellows B. A prospective evaluation of bleeding risk of interventional techniques in chronic pain. Pain Physician 2011; 14:317-329.

9. Manchikanti L, Malla Y, Wargo BW, Cash KA, Pampati V, Fellows B. A prospective evaluation of complications of 10,000 fluoroscopically directed epidural injections. Pain Physician 2012; 15:131-140.

10. Manchikanti L, Benyamin RM, Swicegood JR, Falco FJE, Datta S, Pampati V, Fellows B, Hirsch JA. Assessment of practice patterns of perioperative management of antiplatelet and antico- botic therapy; however, the majority of the reports show that these occurrences have been reported in patients where antiplatelet therapy has been stopped or the patient was not on antiplatelet therapy. $\mathrm{Pa}$ tient selection, understanding the risk benefit ratio, and using appropriate precautions, diligence when performing the procedures, and attention after the procedure to any complaints of unusual axial pain at the site of injection are the most important aspects.

agulant therapy in interventional pain management. Pain Physician 2012; 15:E955-E968.

11. Benyamin RM, Vallejo R, Wang V, Kumar N, Cedeño DL, Tamrazi A. Acute epidural hematoma formation in cervical spine after interlaminar epidural steroid injection despite discontinuation of clopidogrel. Reg Anesth Pain Med 2016; 41:398-401.

12. Jenkie EJ, Benyamin RM, Manchikanti L. Fish oil as a potential contributor to epidural hematoma following cervical epidural steroid injection: A case report and focused literature review. IPM Reports 2017: 1:19-26.

13. Swicegood JR, Manchikanti L, Benyamin RM, Hirsch JA. Two cases of acute epidural hematoma formation after cervical interlaminar epidural steroid injections. IPM Reports 2017; 1:27-32.

14. Chien GC, McCormick Z, Araujo M, Candido KD. The potential contributing effect of ketorolac and fluoxetine to a spinal epidural hematoma following a cervical interlaminar epidural steroid injection: A case report and narrative review. Pain Physician 2014; 17:E385-E395.

15. Manchikanti L, Falco FJE, Benyamin RM, Caraway DL, Kaye AD, Helm II S, Wargo BW, Hansen H, Parr AT, Singh V, Swicegood JR, Smith HS, Schultz DM, Malla Y, Hirsch JA. Assessment of bleeding risk of interventional techniques: A best evidence synthesis of practice patterns and perioperative management of anticoagulant and antithrombotic therapy. Pain Physician 2013; 16:SE261-SE318.

16. Manchikanti L, Hirsch JA. Neurological complications associated with epidural steroid injections. Curr Pain Headache Rep 2015; 19:482.

17. Kim M, Park KS. Intracranial chronic subdural hematoma presenting with intractable headache after cervical epidural steroid injection. J Korean Neurosurg Soc 2015; 58:144-146.

18. Reitman CA, Watters W 3rd. Subdural hematoma after cervical epidural steroid injection. Spine (Phila Pa 1976) 2002; 27:E174E176.

19. Williams KN, Jackowski A, Evans PJ. Epidural haematoma requiring surgical decompression following repeated cervical epidural steroid injections for chronic pain. Pain 1990; 42:197-199.

20. Xu R, Bydon M, Gokaslan ZL, Wolinsky JP, Witham TF, Bydon A. Epidural steroid injection resulting in epidural hematoma in a patient despite strict adherence to anticoagulation guidelines. $J$ Neurosurg Spine 2009; 11:358-364.

21. Fitzgibbon DR. Chronic pain management: ASA closed claims project. Anesthesiology 2004; 100:98-105.

22. Rathmell JP, Michna E, Fitzgibbon DR, Stephens LS, Posner 
$\mathrm{KL}$, Domino KB. Injury and liability associated with cervical procedures for chronic pain. Anesthesiology 2011; 114:918-926.

23. Norouze S, Benzon HT, Provenzano DA, Buvanendran A, De Andres J, Deer TR, Rauck R, Huntoon MA. Interventional spine and pain procedures in patients on antiplatelet and anticoagulant medications: Guidelines from the American Society of Regional Anesthesia and Pain Medicine, the European Society of Regional Anaesthesia and Pain Therapy, the American Academy of Pain Medicine, the International Neuromodulation Society, the North American Neuromodulation Society, and the World Institute of Pain. Reg Anesth Pain Med 2015; 40:182-212.

24. Bogduk N (ed). Practice Guidelines for Spinal Diagnostic and Treatment Procedures. 2nd edition. International Spine Intervention Society (ISIS), San Francisco, 2013.

25. Groen RJ, Ponssen H. The spontaneous spinal epidural hematoma. A study of the etiology. J Neurol Sci 1990; 98:121-138.

26. U HS, Wilson CB. Postoperative epidural hematoma as a complication of anterior cervical discectomy. Report of three cases. J Neurosurg 1978; 49:288-291.

27. Horlocker TT, Wedel DJ. Neuraxial block and low-molecular weight-heparin: Balancing perioperative analgesia and thromboprophylaxis. Reg Anesth Pain Med 1998; 23:164-177.

28. Yoo HS, Park SW, Han JH, Chung JY, Yi JW, Kang JM, Lee BJ, Kim DO. Paraplegia caused by an epidural hematoma in a patient with unrecognized chronic idiopathic thrombocytopenic purpura following an epidural steroid injection. Spine 2009; 34:E376-E379.

29. Takahashi K, Koewa F, Tayama H, Satomi A, Akizawa T, Ideura T. A case of acute spontaneous epidural haematoma in a chronic renal failure patient undergoing haemodialysis: Successful outcomes with surgical management. Nephrol Dial Transplant 1999; 14:2499-2501.

30. Yokota S, Hirabayashi Y, Wakata M, Maruyama Y, Mukoyama A, Nomura M, Hamada S, ljichi N, Matsumoto T, Shima M. Mild hemophilia A diagnosed at the onset of acute epidural hematoma after lumbar epidural block. Rinsho Ketsueki 2011; 52:78-83.
31. Kreppel D, Antoniadis G, Seeling W. Spinal hematoma: A literature survey with meta-analysis of 613 patients. Neuorsurg Rev 2003; 26:1-49.

32. Vandermeulen EP, Van Aken H, Vermylen J. Anticoagulants and spinal-epidural anesthesia. Anesth Analg 1994; 79:1165-1177.

33. Wulf $\mathrm{H}$. Epidural anesthesia and spinal haematoma. Can J Anaesth 1996; 42:1260-1273.

34. Stoll A, Sanchez M. Epidural hematoma after epidural block: Implications for its use in pain management. Surg Neurol 2002; 57:235-240.

35. Lim SH, Hong BY, Cho YR, Kim HS, Lee JI, Kim HW, Ko YJ. Relapsed spontaneous spinal epidural hematoma associated with aspirin and clopidogrel. Neurol Sci 2011; 32:687-689.

36. Latner AW. Patient's death lands clinician in court for advising cessation of aspirin therapy. MPR, July 12, 2016.

37. Huntoon MA. Anatomy of the cervical intervertebral foramina: Vulnerable arteries and ischemic neurologic injuries after transforaminal epidural injections. Pain 2005; 117:104-111.

38. Rathmell JP, Benzon HT, Dreyfuss P, Huntoon M, Wallace M, Baker R, Riew KD, Rosenquist RW, Aprill C, Rost NS, Buvanendran A, Kreiner DS, Bogduk N, Fourney DR, Fraifeld E, Horn S, Stone J, Vorenkamp K, Lawler G, Summers J, Kloth D, O'Brien D Jr, Tutton S. Safeguards to prevent neurologic complications after epidural steroid injections: Consensus opinions from a multidisciplinary working group and national organizations. Anesthesiology 2015; 122:974-984.

39. Racoosin JA, Seymour SM, Cascio L, Gill R. Serious neurologic events after epidural glucocorticoid injection--the FDA's risk assessment. N Engl J Med 2015; 373:2299-2301.

40. Manchikanti L, Falco FJE. Safeguards to prevent neurologic complications after epidural steroid injections: Analysis of evidence and lack of applicability of controversial policies. Pain Physician 2015; 18:E129-E138. 